\title{
Fever Among Preschool Aged Children: A Cross- Sectional Study Assessing Lebanese Parents' Knowledge, Attitudes and Practices on Pediatric Fever Assessment and Management
}

Fouad Sakr ( $\nabla$ fouad.sakr@liu.edu.lb )

Lebanese International University

\section{Zeina Akiki}

Lebanese University

Marwan Akel

Lebanese International University

Diana Malaeb

Lebanese International University

Mariam Dabbous

Lebanese International University

Pascale Salameh

Lebanese University

\section{Research Article}

Keywords: Knowledge, attitude, practice, fever, antipyretic, pediatric, parents

Posted Date: December 28th, 2021

DOI: https://doi.org/10.21203/rs.3.rs-1170344/v1

License: (c) (1) This work is licensed under a Creative Commons Attribution 4.0 International License.

Read Full License 


\section{Abstract \\ Background}

The existing literature demonstrates insufficient parental knowledge around fever, and international guidelines suggest studying parents' perceptions and practices in treating febrile sickness. This study investigated parental knowledge, attitudes and practices toward fever in preschool children to help address all pointed gaps and provide information with the aim of supporting clinical reports for parental education.

\section{Methods}

A cross-sectional study design was used to explore parental experiences with fever. Participants were recruited randomly from schools all over Lebanon targeting the preschool divisions to include parents of children aged 5 years or less. An electronic self-administered questionnaire was sent to the parents through the schools' emails and e-learning mobile applications, with a separate message encouraging parents to take time to fill carefully the survey.

\section{Results}

A total of 733 parents were included in the study. Only $44 \%$ identified fever correctly according to the recognized definition by international guidelines. A significant association between parents' knowledge of antibiotics and years of parenting experience was found ( $\mathrm{ORa}=4.23,95 \% \mathrm{Cl} 1.41-12.68, \mathrm{P}=0.01)$. Other sociodemographic factors that were significantly associated with parents' knowledge of antibiotics were age $(\mathrm{ORa}=3.42,95 \% \mathrm{Cl} 1.09-10.73, \mathrm{P}=0.036)$ and education level $(\mathrm{ORa}=7.99,95 \% \mathrm{Cl} 3.71-17.23$, $\mathrm{P}<0.001)$. Greater than $75 \%$ usually give their children antipyretics without consulting a doctor. Approximately one-quarter of parents $(26.3 \%)$ consulted different doctors at the same time, of which more than half (58.4\%) had received different medical information.

\section{Conclusions}

This research determines deficiencies in parents' knowledge of fever with some malpractices in its management. It provides insight for healthcare providers to empower parental experiences by offering the necessary information to enhance general outcomes of febrile sickness.

\section{Background}

Fever is well defined as a regulated elevation in body temperature of $38^{\circ} \mathrm{C}$ or more $(1,2)$. It is normal in childhood and rarely indicates a serious illness, although it highly concerns parents and causes anxiety (3-6). Fever phobia is characterized by parents' overconcern and exaggerated unrealistic misconception 
around fever (7). Parental reporting of febrile sickness and seeking medical attention are common. In fact, feverish conditions remain one of the common reasons for visiting pediatricians, general practitioners and emergency departments, as well as out-of-hours care to seek medical advice and reassurance $(8,9)$.

Pediatric fever is frequently treated improperly and unnecessarily, resulting in misuse of public healthcare facilities or safety problems that might endanger children (10). Antipyretics and antibiotics are extensively utilized for treating febrile children (11-13). Eldalo A. reported that the most frequent medications self-utilized to manage pediatric fever in Saudi Arabic are paracetamol followed by antibiotics (14). Parents routinely lessen mild fever to prevent complications. Nonetheless, fever should be managed accurately, and international guidelines advise the careful use of antipyretics only when necessary $(15,16)$. The substantial misuse of antibiotics to manage pediatric fever is frequently associated with antimicrobial resistance, a global issue that has been reported in developing countries (17). Moreover, a considerable number of medication errors in children are attributable to antipyretics, and subsequent parental apprehension is increasing (9). Some parents have deficient knowledge regarding antipyretic administration, adverse events, dosing, and toxicity. Lack of this necessary knowledge can lead to negative outcomes on the child's health and the healthcare system. For instance, acetaminophen (paracetamol) underdosing might lead to unsatisfactory management of fever and additional needless medical consultations, consequently resulting in higher healthcare expenses and the overuse of antibiotics (18).

The American Academy of Pediatrics has issued a clinical report about fever and antipyretic use in children to educate parents about precise management and to minimize fever phobia (19). Research indicates parental misuse of antipyretics by being overdosed or underdosed or inaccurately alternated while managing a fever $(8,11,20)$. There are limited studies assessing the knowledge, attitude and beliefs of parents regarding fever. Most published studies have been carried out in secondary care, in which acute distress of children and parents may possibly yield biased perceptions and impact responses $(9,21)$. Studies assessing pediatric self-care behaviors are still recommended to ensure the careful management of fever safely and effectively and to minimize unnecessary primary care visits.

The United Kingdom National Institute for Health and Care Excellence guidelines development group for the assessment and management of febrile sickness in young children suggests studying parental perception and practice in managing fever and using home-based medications (3). Lebanon is an uppermiddle income country that is currently confronting a devastating socioeconomic and financial crisis that conceivably ranks among the top three most severe crisis episodes worldwide and therefore depreciates the national public and health necessities $(22,23)$. Multiple classes of medications are available for overthe-counter use in the Lebanese community for self-care, including antibiotics and antipyretics (24). Nevertheless, there is a scarcity of data around pediatric fever and parental knowledge and practices regarding its management. This study investigated parental knowledge, attitudes and practices toward fever in preschool children to help address all pointed gaps and provide information with the aim of supporting clinical reports for parental education. 


\section{Methods}

\section{Study design and setting}

A cross-sectional study design was used to explore parental experiences about fever. Participants were recruited from schools all over Lebanon targeting the preschool divisions to include parents of children aged 5 years or less. Schools were selected by a multistage cluster sampling technique from all over Lebanon to minimize selection bias. Sample variation was maximized by including large and small schools that could be public or private in urban and rural settings. Selected schools were approached through phone calls and emails to elucidate the study purpose and procedure. Participating schools had to approve the study proposal and help deliver the study survey to the parents. Surveying took place from November 2020 until June 2021. A total of 12 schools were enrolled in the study following their administrative approval. The schools were distributed over Lebanon, including 4 schools in the capital Beirut, 2 in the North governorate, 2 in the South governorate, 2 in Bekaa, and 2 in Mount Lebanon. The total number of parents that were targeted exceeded 1000. An electronic self-administered questionnaire through Google Forms was sent to the parents through the schools' emails and e-learning mobile applications. This approach was chosen because it is the most common school-house communication pattern in Lebanon following repetitive lockdowns due to the COVID-19 pandemic. A separate message was also sent by each school to the parents, encouraging them to take time to fill out the survey carefully. The schools' messages uniformly highlighted the importance of contributions and their impact on nationwide childhood health.

\section{Questionnaire and outcomes}

A previously developed and validated questionnaire in the Netherlands and Ireland was utilized with permission $(2,25)$. The questionnaire was translated into the Arabic language, the native language of Lebanon, by 2 authors using forward backward translation methods and customized to reflect the cultural pattern and practices in Lebanon. Conflicts were resolved by consensus. A sample of 15 parents was initially used to pilot the study. The survey consisted of 32 questions with subsets distributed over 4 parts. The first part included questions about the sociodemographic characteristics of the participants. The second part assessed parents' knowledge of fever and the correct use of antimicrobials. The third part evaluated parental attitudes and practices regarding fever assessment and management and the utilization of antipyretics. Parents answered Yes/No and Agree/Disagree questions, and responses utilized Likert Scales. The last part evaluated prospects from pursuing medical attention and identified information resources. The primary outcome measure was to assess parental knowledge about the precise definition of fever and causes, correct use of medications, and to evaluate the impact of sociodemographic factors on this knowledge. The secondary outcome measures were to assess parental attitudes and practices of fever management, sources of information, and reasons to seek primary medical attention.

\section{Ethical aspects}


The study protocol was approved by the ethics and research committee of the School of Pharmacy at Lebanese International University (2020RC-063-LIUSOP). All methods were performed in accordance with the relevant guidelines and regulations. Anonymity and confidentiality of all participants were warranted, as personal identifiers were not traced during the data collection and analysis. All parents agreed to participate and signed an electronic informed consent form before being able to fill out the survey.

\section{Sample size calculation}

CDC's Epi Info version 7.2.4. for population surveys was used to calculate the required minimal sample size. The expected frequency was kept at $50 \%$ to yield the largest minimum sample size. Accordingly, a minimum of 384 participants were required to allow for adequate power of statistical analysis and produce a $95 \%$ confidence level with an acceptable margin of error of $5 \%$.

\section{Statistical analysis}

Responses were extracted from Google Forms into Microsoft Excel and then coded and analyzed using IBM Statistical Package for Social Sciences (IBM SPSS) version 26.0. The sociodemographic characteristics of the parents were assessed by descriptive statistics. Categorical variables were expressed as frequencies and percentages and were evaluated in the bivariate analyses using chi-square or Fisher's exact test. Multivariable analyses utilizing three binomial logistic regression models were utilized to determine predictors of the dependent variables "good knowledge of fever definition" and "good knowledge of antibiotic use". All covariates with a p value lower than 0.2 in the bivariate analyses were included in the models to preclude potential confounders. The results were reported as adjusted odds ratios (ORa) with a $95 \%$ confidence interval. The level of significance was set at $p \leq 0.05$ and an acceptable margin of error $=5 \%$.

\section{Results}

\section{Sociodemographic characteristics}

A total of 733 parents completed the survey, producing a response rate greater than $70 \%$. The majority of respondents were Lebanese $(93.3 \%, \mathrm{n}=616)$, as parents representing other nationalities in Lebanon also participated in this study. More than $60 \%$ of the participating parents had a university degree, of which only $4.4 \%$ were in the medical field. Most of the participants (47.8\%) had 2 children, followed by 3 children $(23.2 \%)$. Only $9.3 \%$ of the parents had a child with an underlying chronic condition that may cause him/her to get sick more often or seriously than other children. The detailed sociodemographic characteristics are presented in Table 1.

Table 1: Sociodemographic characteristics of participants 


\section{Participants}

$N(\%)$

Survey respondents

- Fathers

- Mothers

665

(90.7)

Age classes

- $\leq 25$ years

- 26 - 30 years

- 31 - 35 years

- 36 - 40 years

- >40 years

Educational level

- University

- High school

- Other level

Nationality

- Lebanese

- Non-Lebanese

Specialty

- Medical

- Para-medical

- Non-Medical 
- Married

- Divorced or widowed

Number of children

- 1

- 2

- 3

- 4

- 5

- >5

First child age

- $\leq 3$ years old

- 4 years old

- 5 years old

- 6 years old

- $>6$ years old

Child/children health status

- Presence of underlying chronic condition (e.g., congenital heart/lung disease, Down's syndrome or other condition that may cause more often or serious sickness)

\section{Parental knowledge on pediatric fever and antimicrobial use}

Less than half of the parents (44\%) identified temperatures at which they defined fever according to the recognized definition of $38{ }^{\circ} \mathrm{C}$ or more. Another $42 \%$ of parents spotted fever at a temperature above the identified definition, and $14 \%$ indicated it below this definition. Parents demonstrated variable knowledge regarding infections and use of medications. Almost half of the parents $(46.9 \%)$ considered that every 
child with fever needs an antipyretic. Most parents (75.3\%) believed that the majority of feverish illnesses don't require an antimicrobial prescription, and $66.2 \%$ were aware that antibiotics are used only to treat bacterial infections.

The multivariable logistic regression analysis between sociodemographic factors and "knowledge of parents on fever definition" showed no significant associations (data not shown). A significant positive association between good parental knowledge on "using antibiotics for every child with fever" and years of parenting experience where the first child's age was 5 years old was found ( $\mathrm{ORa}=4.23,95 \% \mathrm{Cl} 1.41$ $12.68, P=0.01$ ). The parental age group of 31 to 35 years had significantly better knowledge on the use of antibiotics for a child with fever $(\mathrm{ORa}=3.42,95 \% \mathrm{Cl} 1.09-10.73, \mathrm{P}=0.036)$. The education level of a university degree was also significantly associated with better knowledge (ORa $=7.99,95 \% \mathrm{Cl} 3.71-17.23$, $P<0.001)$. Regarding parental knowledge for "not using antibiotics to treat a viral infection", positive significant associations were found with having a university degree $(\mathrm{ORa}=8.51,95 \% \mathrm{Cl} 2.58-28.14, \mathrm{P}$ $<0.01)$ or a high school degree $(\mathrm{ORa}=4.02,95 \% \mathrm{Cl} 1.14-14.19, \mathrm{P}=0.031)$. Moreover, significant positive associations were observed for parents working in the medical or paramedical fields (ORa $=11.21,95 \% \mathrm{Cl}$ 3.02-41.64; and 3.43, 2.04-5.76, respectively) with $P$ values $<0.001$ ). The association between the sociodemographic predictors and parents' knowledge of antibiotics is shown in Tables 2 and 3 , respectively.

Table 2: Association between sociodemographic predictors and good parental knowledge on the dependent variable "every child with fever needs antibiotic" 


\begin{tabular}{|c|c|c|c|}
\hline Variable & Adjusted odds ratio & $95 \%$ confidence interval & $P$ value \\
\hline \multicolumn{4}{|l|}{ Gender } \\
\hline \multicolumn{4}{|l|}{ - Mother ${ }^{*}$} \\
\hline - Father & 1.62 & $0.75-3.52$ & 0.223 \\
\hline \multicolumn{4}{|l|}{ Age classes } \\
\hline \multirow{5}{*}{$\begin{array}{l}\cdot \leq 25^{*} \\
\cdot-26-30 \\
\cdot-31-35 \\
\cdot-36-40 \\
\cdot->40\end{array}$} & & & \\
\hline & 2.91 & $0.92-9.24$ & 0.070 \\
\hline & 3.42 & $1.09-10.73$ & $0.036^{* *}$ \\
\hline & 3.27 & $0.99-10.83$ & 0.053 \\
\hline & 1.68 & $0.44-6.36$ & 0.448 \\
\hline \multicolumn{4}{|l|}{ Education level } \\
\hline \multirow{3}{*}{$\begin{array}{l}\text { - Other }{ }^{\star} \\
\text { - University } \\
\text { - High school }\end{array}$} & & & \\
\hline & 7.99 & $3.71-17.23$ & $<0.001^{\star \star}$ \\
\hline & 1.86 & $0.82-4.23$ & 0.137 \\
\hline \multicolumn{4}{|l|}{ Nationality } \\
\hline \multicolumn{4}{|l|}{ - Lebanese* } \\
\hline - Non-Lebanese & 0.55 & $0.20-1.52$ & 0.246 \\
\hline \multicolumn{4}{|l|}{ Specialty } \\
\hline \multicolumn{4}{|l|}{ - Nonmedical* } \\
\hline \multirow{2}{*}{$\begin{array}{l}\text { - Medical } \\
\text { - Paramedical }\end{array}$} & 1.57 & $0.38-6.46$ & 0.536 \\
\hline & 1.22 & $0.63-2.35$ & 0.560 \\
\hline \multicolumn{4}{|l|}{ Marital status } \\
\hline \multicolumn{4}{|l|}{ - Married $^{*}$} \\
\hline - Divorced or widowed & 2.44 & $0.84-7.11$ & 0.102 \\
\hline \multicolumn{4}{|l|}{ Number of children } \\
\hline \multicolumn{4}{|l|}{ - $1^{*}$} \\
\hline $\begin{array}{l}\cdot 2 \\
\cdot 3\end{array}$ & 0.78 & $0.38-1.57$ & 0.480 \\
\hline - 4 & 0.98 & $0.41-2.32$ & 0.956 \\
\hline $\begin{array}{ll}\cdot & 5 \\
\cdot & >5\end{array}$ & 0.87 & $0.29-2.66$ & 0.808 \\
\hline
\end{tabular}




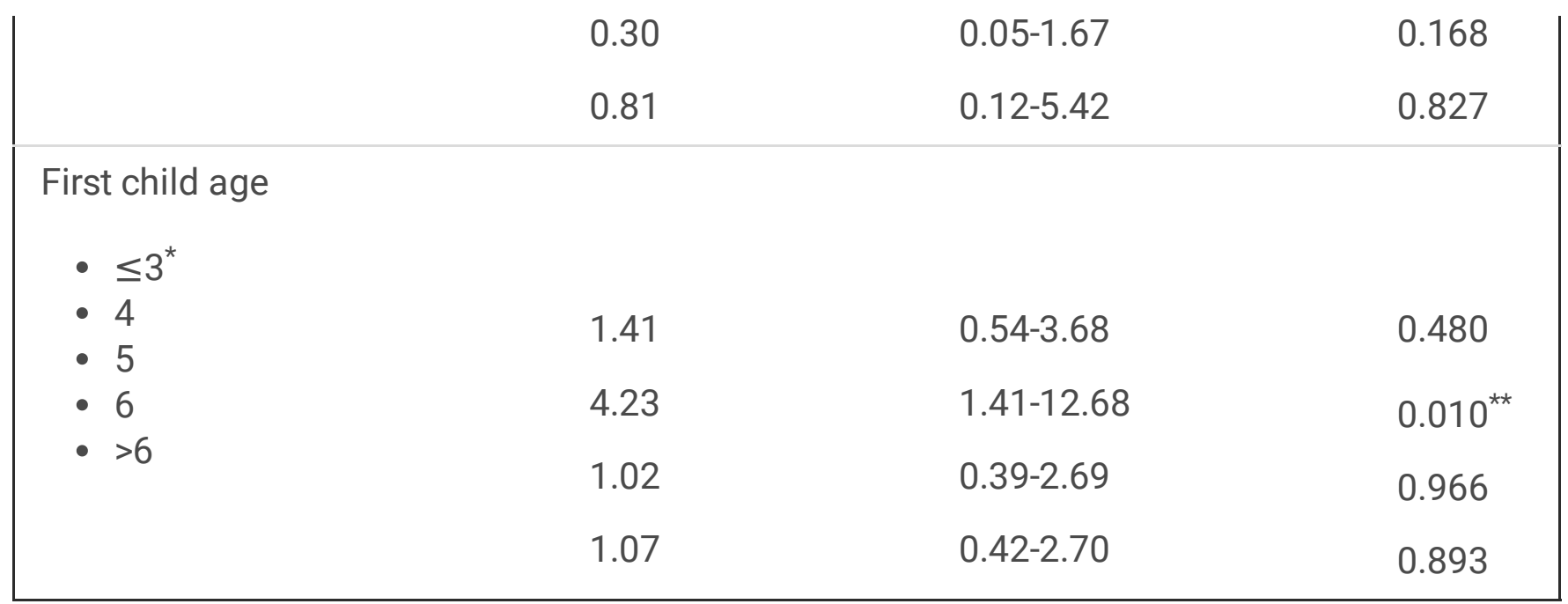

${ }^{*}$ Reference

${ }^{* *}$ Statistically significant

Table 3: Association between sociodemographic predictors and good parental knowledge on the dependent variable "antibiotics are not used to cure infections caused by viruses" 


\begin{tabular}{|c|c|c|c|}
\hline Variable & Adjusted odds ratio & $95 \%$ confidence interval & $P$ value \\
\hline \multicolumn{4}{|l|}{ Gender } \\
\hline \multicolumn{4}{|l|}{ - Mother ${ }^{*}$} \\
\hline - Father & 1.02 & $0.50-2.11$ & 0.955 \\
\hline \multicolumn{4}{|l|}{ Age classes } \\
\hline \multicolumn{4}{|l|}{ - $\leq 25^{\star}$} \\
\hline \multirow{4}{*}{$\begin{array}{l}\text { - } 26-30 \\
\text { - } 31-35 \\
\text { - } 36-40 \\
\text { - }>40\end{array}$} & 0.80 & $0.25-2.56$ & 0.702 \\
\hline & 0.79 & $0.25-2.52$ & 0.691 \\
\hline & 0.55 & $0.16-1.85$ & 0.332 \\
\hline & 0.79 & $0.21-3.04$ & 0.736 \\
\hline \multicolumn{4}{|l|}{ Education level } \\
\hline \multirow{3}{*}{$\begin{array}{l}\text { - Other } \\
\text { - University } \\
\text { - High school }\end{array}$} & & & \\
\hline & 8.51 & $2.58-28.14$ & $<0.001^{\star \star}$ \\
\hline & 4.02 & $1.14-14.19$ & $0.031^{\star \star}$ \\
\hline \multicolumn{4}{|l|}{ Nationality } \\
\hline \multicolumn{4}{|l|}{ - Lebanese* } \\
\hline - Non-Lebanese & 2.69 & $0.86-8.48$ & 0.090 \\
\hline \multicolumn{4}{|l|}{ Specialty } \\
\hline \multicolumn{4}{|l|}{ - Nonmedical* } \\
\hline \multirow{2}{*}{$\begin{array}{l}\text { - Medical } \\
\text { - Paramedical }\end{array}$} & 11.21 & $3.02-41.64$ & $<0.001^{\star \star}$ \\
\hline & 3.43 & $2.04-5.76$ & $<0.001^{* *}$ \\
\hline \multicolumn{4}{|l|}{ Marital status } \\
\hline \multicolumn{4}{|l|}{ - Married $^{*}$} \\
\hline - Divorced or widowed & 4.47 & $0.96-20.82$ & 0.056 \\
\hline \multicolumn{4}{|l|}{ Number of children } \\
\hline \multicolumn{4}{|l|}{ - $1^{*}$} \\
\hline $\begin{array}{l}\cdot 2 \\
\cdot 3\end{array}$ & 1.29 & $0.73-2.27$ & 0.388 \\
\hline - 4 & 1.26 & $0.62-2.57$ & 0.526 \\
\hline $\begin{array}{l}\cdot 5 \\
\cdot>5\end{array}$ & 2.27 & $0.82-6.23$ & 0.113 \\
\hline
\end{tabular}




\begin{tabular}{|llll|} 
& 1.74 & $0.35-8.73$ & 0.499 \\
\hline First child age & 2.30 & $0.32-16.34$ & 0.406 \\
$\bullet \leq 3^{*}$ & & & \\
$\cdot 4$ & & & \\
$\cdot 5$ & 1.26 & $0.55-2.88$ & 0.585 \\
$\cdot 6$ & 0.98 & $0.42-2.29$ & 0.963 \\
$\cdot>6$ & 0.68 & $0.28-1.63$ & 0.387 \\
& 0.61 & $0.26-1.41$ & 0.246 \\
\hline
\end{tabular}

${ }^{*}$ Reference

${ }^{* *}$ Statistically significant

\section{Attitudes and practices}

Parents' practices on fever are reported in table 4. A total of 727 parents, representing $99.9 \%$, treated a feverish child with antipyretics. The initiation of the antipyretic was mostly identified at a temperature of $38{ }^{\circ} \mathrm{C}$ followed by $38.5{ }^{\circ} \mathrm{C}$ ( $40.9 \%$ and $33.9 \%$, respectively). Greater than $75 \%$ stated that they usually give their children antipyretics without consulting a doctor. Reasons to consider antipyretics included less fluid intake ( $50.9 \%$ agree, $25.5 \%$ strongly agree); drowsiness ( $51.8 \%$ agree, $37.3 \%$ strongly agree); irritability or nonstoppable crying (44.8\% agree, $28.5 \%$ strongly agree); and pain (48.9\% agree, $38.9 \%$ strongly agree) (table 5).

Table 4: Parents' practices on fever 


\begin{tabular}{|lll|}
\hline Statement & Answer & $\begin{array}{l}\text { Frequency } \\
(\%)\end{array}$ \\
\hline $\begin{array}{l}\text { Do you ever treat your child with fever inhibitors like acetaminophen } \\
\text { (paracetamol) when he/she has a fever? }\end{array}$ & Yes & $727(99.9)$ \\
\hline If so, above what temperature? & No & $1(0.1)$ \\
& 36 & $6(0.8)$ \\
& 36.5 & $1(0.1)$ \\
& 37 & $4(0.5)$ \\
& 37.5 & $55(7.5)$ \\
& 38 & $300(40.9)$ \\
\hline $\begin{array}{l}\text { Do you administer medication to your child like acetaminophen } \\
\text { (paracetamol) without first consulting a doctor? }\end{array}$ & 38.5 & $249(33.9)$ \\
\hline
\end{tabular}

Table 5: Parental attitudes toward antipyretic use 


\begin{tabular}{|c|c|c|}
\hline Statement & Answer & $\begin{array}{l}\text { Frequency } \\
(\%)\end{array}$ \\
\hline \multirow[t]{4}{*}{ When my child has a fever and takes in less fluids } & Strongly agree & $163(25.5)$ \\
\hline & Agree & $325(50.9)$ \\
\hline & Disagree & $133(20.8)$ \\
\hline & $\begin{array}{l}\text { Strongly } \\
\text { disagree }\end{array}$ & $18(2.8)$ \\
\hline \multirow[t]{4}{*}{ When my child has a fever and is drowsy } & Strongly agree & $243(37.3)$ \\
\hline & Agree & $337(51.8)$ \\
\hline & Disagree & $60(9.2)$ \\
\hline & $\begin{array}{l}\text { Strongly } \\
\text { disagree }\end{array}$ & $11(1.7)$ \\
\hline \multirow[t]{4}{*}{ When my child has a fever and a skin rash } & Strongly agree & $137(21.8)$ \\
\hline & Agree & $220(35.0)$ \\
\hline & Disagree & $247(39.3)$ \\
\hline & $\begin{array}{l}\text { Strongly } \\
\text { disagree }\end{array}$ & $24(3.8)$ \\
\hline \multirow[t]{4}{*}{ When my child has a fever and is crying unstoppably } & Strongly agree & $182(28.5)$ \\
\hline & Agree & $286(44.8)$ \\
\hline & Disagree & $150(23.5)$ \\
\hline & $\begin{array}{l}\text { Strongly } \\
\text { disagree }\end{array}$ & $21(3.3)$ \\
\hline \multirow[t]{4}{*}{ When my child has a fever and is in pain } & Strongly agree & $262(38.9)$ \\
\hline & Agree & $329(48.9)$ \\
\hline & Disagree & $68(10.1)$ \\
\hline & $\begin{array}{l}\text { Strongly } \\
\text { disagree }\end{array}$ & $14(2.1)$ \\
\hline \multirow{4}{*}{$\begin{array}{l}\text { When my child has a fever and is breathing differently (faster or } \\
\text { moaning) }\end{array}$} & Strongly agree & $176(27.5)$ \\
\hline & Agree & 236 (36.9) \\
\hline & Disagree & $193(30.2)$ \\
\hline & $\begin{array}{l}\text { Strongly } \\
\text { disagree }\end{array}$ & $32(5.0)$ \\
\hline
\end{tabular}


Examination of practices toward antipyretics shows that less than half of parents (45.8\%) believe that they cannot alternate between two different fever-reducing agents, or they are not sure $(11.6 \%)$. The remaining $42.4 \%$ alternate between different antipyretics, but they do not mix them together. Acetaminophen (paracetamol) is the most commonly used antipyretic. It is utilized by $89.9 \%$ of parents, followed by ibuprofen and diclofenac. The majority of parents $(89.2 \%)$ also thought that paracetamol is the most preferred antipyretic agent. Half of the parents (50.5\%) preferred to use both syrups and suppositories, and $46.7 \%$ preferred to use syrups alone. Approximately three-quarters of parents $(73.5 \%)$ think that different forms of a drug have the same effect.

With respect to measuring temperature and monitoring fever, slightly more than half of the parents $(55.9 \%)$ use a rectal thermometer. Other routes and methods of assessment mainly included using a tympanic thermometer or a thermometer under the armpit $(26.1 \%$ and $8.2 \%$, respectively). Whereas $6.1 \%$ depend on skin palpation only. The frequency of temperature measurement varied between 3 and more than 5 times daily. The frequencies of daily temperature measurements are shown in figure 1 .

\section{Seeking medical care and parental satisfaction}

A considerable percentage of parents $(91.7 \%)$ had visited a pediatrician or general practitioner for their child's fever. Persistence of fever beyond 3 days and fever accompanied by breathing differently, skin rash, irritability, or pain were the reasons for these visits. Table 6 reports reasons for seeking medical care. Assessment of post visit satisfaction reveals that $70 \%$ are usually very satisfied, and they are given enough time and information. Approximately one-quarter of parents $(26.3 \%)$ consulted different doctors at the same time, of which more than half $(58.4 \%)$ had received different medical information.

Table 6: Reasons for seeking medical care 


\begin{tabular}{|c|c|c|}
\hline Statement & Answer & $\mathbf{N}(\%)$ \\
\hline \multirow[t]{5}{*}{ When my child has a fever and takes in less fluids } & Never & $31(4.6)$ \\
\hline & Rarely & $100(14.9)$ \\
\hline & Sometimes & $187(27.9)$ \\
\hline & Most of the times & $165(24.6)$ \\
\hline & Always & $188(28.0)$ \\
\hline \multirow[t]{5}{*}{ When my child has a fever and is drowsy } & Never & $23(3.4)$ \\
\hline & Rarely & $61(9.0)$ \\
\hline & Sometimes & $170(25.1)$ \\
\hline & Most of the times & $190(28.1)$ \\
\hline & Always & $233(34.4)$ \\
\hline \multirow[t]{5}{*}{ When my child has a fever and a skin rash } & Never & $19(2.8)$ \\
\hline & Rarely & $18(2.6)$ \\
\hline & Sometimes & $63(9.2)$ \\
\hline & Most of the times & $152(22.1)$ \\
\hline & Always & $435(63.3)$ \\
\hline \multirow[t]{5}{*}{ When my child has a fever and is crying unstoppably } & Never & $21(3.1)$ \\
\hline & Rarely & $52(7.6)$ \\
\hline & Sometimes & 103 (15.1) \\
\hline & Most of the times & $137(20.1)$ \\
\hline & Always & $367(54.0)$ \\
\hline \multirow[t]{5}{*}{ When my child has a fever and is in pain } & Never & $13(1.9)$ \\
\hline & Rarely & $26(3.7)$ \\
\hline & Sometimes & $86(12.4)$ \\
\hline & Most of the times & $132(19.0)$ \\
\hline & Always & $437(63.0)$ \\
\hline \multirow[t]{4}{*}{ When my child has a fever and is breathing differently } & Never & $10(1.5)$ \\
\hline & Rarely & $22(3.2)$ \\
\hline & Sometimes & $48(7.0)$ \\
\hline & Most of the times & $116(17.0)$ \\
\hline
\end{tabular}




\begin{tabular}{|lll|}
\hline When my child has a fever for more than three days & Always & $487(71.3)$ \\
& Never & $11(1.5)$ \\
& Rarely & $14(2.0)$ \\
& Sometimes & $16(2.2)$ \\
& Most of the times & $57(8.0)$ \\
& Always & $618(86.3)$ \\
\hline
\end{tabular}

\section{Sources of information}

More than half of the parents $(68.1 \%, \mathrm{n}=491)$ preferred to obtain information about fever before their child gets sick. Pediatricians were identified by $69.1 \%$ of parents as the preferable source of information for children's fever. Other sources of information included general practitioners and the internet. Sources of information regarding pediatric fever are shown in figure 2 .

\section{Discussion}

The present study indicates that parents' knowledge about the appropriate definition of fever is inadequate. This was reflected by identifying fever by many parents as a temperature that is either higher or less than the realized level. The sociodemographic characteristics were not prognostic of this knowledge. Acceptable knowledge about antibiotics, on the other hand, was observed. The majority of parents understand the rationale of prescribing antibiotics and their correct use.

Approximately half of the population in this study identified a false definition of fever when compared with existing research $(22 \%-63.1 \%)(2,9,25-31)$. The recognition of knowledge gaps among different proportions of each population could be attributable to variation in sample size. The larger sample size in this research and some other studies have elucidated more incorrect fever definitions. Those studies have reported a prognostic role of sociodemographic characteristics on parental knowledge of fever definition. Our multivariable analysis showed no significant association between sociodemographic factors and better or deficient knowledge regarding fever definition. Nonetheless, we found a better knowledge about antibiotic utilization in febrile sickness that was significantly associated with years of parenting experience, age and level of education.

Erkek et al. reported a significant association between maternal level of education and knowledge on correct fever definition (32). We found that the level of education does not appear to impact incorrect responses, as the inclusion of substantially educated people was not associated with a better link between education and health literacy. This implies that all parents should receive adequate information on fever description regardless of their level of education. Moreover, our results do not appear to be 
confounded by parental gender, as our multivariable analysis has shown no significant association between the gender of the responding parent and the level of knowledge.

Practices regarding antipyretic utilization reflect that parents self-treat a feverish child with various antipyretic agents and dosage forms. In contrast to previous research reflecting the possibility of an association between a higher level of education and more frequent medication (25), this research included a large proportion of highly educated individuals who did not recognize the concept of antipyretic alternation. We found that approximately half of the parents did not recognize the concept of alternating between two fever-reducing agents. Our results are consistent with the findings of previous research, which reported that less than one-quarter of the parents alternate between antipyretics (33). This could be the result of consultations provided by pediatricians and general practitioners, as international guidelines advocate against alternating antipyretics to minimize the risk of dosing errors and toxicity (34).

Malpractices regarding antipyretics appear to be related to their indications, as parents initiate or continue antipyretic therapy if the child has accompanying symptoms, including reduced fluid intake, drowsiness and irritability. This could be attributed to fear of fever. Our study did not examine in-depth parental fears and fever phobia or the consequences on parental practices. Existing literature suggests that fever phobia is highly prevalent (35-38), and it may affect attitudes and patterns of use of antipyretics $(25,38-40)$. The current study adds to the literature that parents tend to regularly seek medical care from a pediatrician when their child has febrile illness with alarming symptoms such as difficulty breathing, rash, pain or persistence of fever. They are usually satisfied following this visit, although one-quarter of parents tend to see or consult multiple doctors at the same time. Parents are also concerned that different doctors provide conflicting information regarding the same sickness, and they prefer to obtain information about fever when their children are not sick.

\section{Implications for practice}

Parents should be educated about the nature of fever and that it is a normal sign with different childhood sickness. This information should be provided before and during illness. Parents should receive information about antipyretics and alternations between different medications. This information should be specific and in well-understandable language. Producing information resources that are clear and accessible would minimize unnecessary visits to pediatricians and enhance the utilization of antipyretics. Awareness campaigns targeting parents in different settings, such as in community pharmacies, schools, or through published media, would also provide effective parental education about fever and improve management outcomes. Future research may reassess knowledge and practices after providing parents with all necessary information. It may further evaluate the key factors in parental counseling that could influence the outcomes of reassessment.

\section{Strengths and limitations}


The large sample size and high response rate are major strengths of this study. The sample was randomly selected from districts all over Lebanon to provide conclusive results. Furthermore, the parents' attitudes were assessed in a nonclinical setting, which minimized unnecessary anxiety and reflected more realistic responses around practices. On the other hand, a main limitation of this study is related to the cross-sectional design, which cannot provide temporality. The majority of participants were mothers, which may limit the generalizability of the findings. The electronic questionnaire may have excluded parents who lack adequate digital literacy. Despite the random sample, this may be associated with a possible risk of selection bias, as the study may have included parents with better literacy and thus better knowledge. In addition, a possible risk of reporting bias or recall bias cannot be excluded, as the questionnaire was self-administered. Finally, residual confounders related to COVID-19 may exist, as the impact of the pandemic was not assessed, as it was beyond the scope of this research. Future work will assess the mediating role of parental fear amid pandemics (COVID-19 and influenza) on attitudes and practices during febrile illness.

\section{Conclusions}

This research determines deficiencies in parents' knowledge of fever with some malpractices in its management. It provides insight for pediatricians and other healthcare providers on the knowledge gaps and malpractice that should be addressed carefully, as they directly or indirectly influence nationwide childhood health. Healthcare professionals should empower parental experiences by offering the necessary information to enhance general outcomes of febrile sickness. Providing and reinforcing this information will help parents take better care of their children and will promote their wellbeing.

\section{Declarations}

\section{Ethics approval and consent to participate}

Not applicable

\section{Consent for publication}

Not applicable

\section{Availability of data and materials}

The datasets used and/or analyzed during the current study are available from the corresponding author on reasonable request.

\section{Competing interests}

The authors declare that they have no competing interests.

\section{Funding}


None

\section{Authors' contributions}

FS conceptualized the study and wrote the manuscript; ZA: analyzed and interpreted the data; MA: collected data; DM and MD: edited the manuscript; PS: supervised the course of the manuscript. All authors read and approved the final manuscript.

\section{Acknowledgments}

The authors thank all parents and schools who contributed to this research.

\section{References}

1. National Collaborating Centre for Women's and Children's Health (UK). Feverish Illness in Children: Assessment and Initial Management in Children Younger Than 5 Years. London: Royal College of Obstetricians \& Gynaecologists (UK); 2013. (National Institute for Health and Care Excellence: Clinical Guidelines).

2. de Bont EG, Francis NA, Dinant G-J, Cals JW. Parents' knowledge, attitudes, and practice in childhood fever: an internet-based survey. Br J Gen Pract J R Coll Gen Pract. 2014 Jan;64(618):e10-16.

3. Fields E, Chard J, Murphy MS, Richardson M, Guideline Development Group and Technical Team. Assessment and initial management of feverish illness in children younger than 5 years: summary of updated NICE guidance. BMJ. 2013 May 22;346:f2866.

4. Purssell E, Collin J. Fever phobia: The impact of time and mortality-a systematic review and metaanalysis. Int J Nurs Stud. 2016 Apr;56:81-9.

5. Teagle AR, Powell CVE. Is fever phobia driving inappropriate use of antipyretics? Arch Dis Child. 2014 Jul;99(7):701-2.

6. Crocetti M, Moghbeli N, Serwint J. Fever phobia revisited: have parental misconceptions about fever changed in 20 years? Pediatrics. 2001 Jun;107(6):1241-6.

7. Hamideh Kerdar S, Himbert C, Martin DD, Jenetzky E. Cross-sectional study of parental knowledge, behaviour and anxiety in management of paediatric fever among German parents. BMJ Open. 2021 Oct;11(10):e054742.

8. Jensen JF, Tønnesen LL, Söderström M, Thorsen H, Siersma V. Paracetamol for feverish children: parental motives and experiences. Scand J Prim Health Care. 2010 Jun;28(2):115-20.

9. Kelly M, Sahm LJ, Shiely F, O'Sullivan R, McGillicuddy A, McCarthy S. Parental knowledge, attitudes and beliefs regarding fever in children: an interview study. BMC Public Health. 2016 Jul 11;16:540.

10. Arias D, Chen TF, Moles RJ. Development and validation of a Fever Management Questionnaire aimed at parents and care givers. J Paediatr Child Health. 2021 Feb;57(2):192-7.

11. Walsh A, Edwards H, Fraser J. Over-the-counter medication use for childhood fever: a cross-sectional study of Australian parents. J Paediatr Child Health. 2007 Sep;43(9):601-6. 
12. Purssell E. Treatment of fever and over-the-counter medicines. Arch Dis Child. 2007 Oct;92(10):9001.

13. Zaki A, Abdel-Fattah M, Bassili A, Arafa M, Bedwani R. The use of medication in infants in Alexandria, Egypt. East Mediterr Health J Rev Sante Mediterr Orient Al-Majallah Al-Sihhiyah Li-Sharq AlMutawassit. 1999 Mar;5(2):320-7.

14. Eldalo A. Saudi parent's attitude and practice about self-medicating their children. Arch Pharm Pract. 2013;4(2):57.

15. Sarrell M, Cohen HA, Kahan E. Physicians', nurses', and parents' attitudes to and knowledge about fever in early childhood. Patient Educ Couns. 2002 Jan;46(1):61-5.

16. de Bont EGPM, Brand PLP, Dinant G-J, van Well GTJ, Cals JWL. [Risks and benefits of paracetamol in children with fever]. Ned Tijdschr Geneeskd. 2014;158(2):A6636.

17. Istúriz RE, Carbon C. Antibiotic use in developing countries. Infect Control Hosp Epidemiol. 2000 Jun;21(6):394-7.

18. Daifallah A, Jabr R, Al-Tawil F, Elkourdi M, Salman Z, Koni A, et al. An assessment of parents' knowledge and awareness regarding paracetamol use in children: a cross-sectional study from Palestine. BMC Public Health. 2021 Dec;21(1):380.

19. Section on Clinical Pharmacology and Therapeutics, Committee on Drugs, Sullivan JE, Farrar HC. Fever and antipyretic use in children. Pediatrics. 2011 Mar;127(3):580-7.

20. Patricia C. Evidence-based management of childhood fever: what pediatric nurses need to know. $J$ Pediatr Nurs. 2014 Aug;29(4):372-5.

21. Kelly M, McCarthy S, O'Sullivan R, Shiely F, Larkin P, Brenner M, et al. Drivers for inappropriate fever management in children: a systematic review. Int J Clin Pharm. 2016 Aug;38(4):761-70.

22. The World Bank. Lebanon I Data [Internet]. 2021 [cited 2021 Jun 5]. Available from: https://data.worldbank.org/country/LB

23. World Bank Group: Middle East and North Africa Region. Lebanon Economic Monitor, Spring 2021: Lebanon Sinking (to the Top 3) [Internet]. World Bank. 2021 [cited 2021 Jun 5]. Available from: https://www.worldbank.org/en/country/lebanon/publication/lebanon-economic-monitor-spring2021-lebanon-sinking-to-the-top-3

24. Farah R, Lahoud N, Salameh P, Saleh N. Antibiotic dispensation by Lebanese pharmacists: A comparison of higher and lower socio-economic levels. J Infect Public Health. 2015 Jan;8(1):37-46.

25. Kelly M, Sahm LJ, Shiely F, O'Sullivan R, de Bont EG, Mc Gillicuddy A, et al. Parental knowledge, attitudes and beliefs on fever: a cross-sectional study in Ireland. BMJ Open. 2017 Jul;7(7):e015684.

26. Cohee LMS, Crocetti MT, Serwint JR, Sabath B, Kapoor S. Ethnic differences in parental perceptions and management of childhood fever. Clin Pediatr (Phila). 2010 Mar;49(3):221-7.

27. Bertille N, Fournier-Charrière $E$, Pons $G$, Chalumeau M. Managing fever in children: a national survey of parents' knowledge and practices in France. PloS One. 2013;8(12):e83469. 
28. Sahm LJ, Kelly M, McCarthy S, O'Sullivan R, Shiely F, Rømsing J. Knowledge, attitudes and beliefs of parents regarding fever in children: a Danish interview study. Acta Paediatr Oslo Nor 1992. 2016 Jan;105(1):69-73.

29. Al-Eissa YA, Al-Sanie AM, Al-Alola SA, Al-Shaalan MA, Ghazal SS, Al-Harbi AH, et al. Parental perceptions of fever in children. Ann Saudi Med. 2000 Jul;20(3-4):202-5.

30. Taveras EM, Durousseau S, Flores G. Parents' Beliefs and Practices Regarding Childhood Fever: A Study of a Multiethnic and Socioeconomically Diverse Sample of Parents. Pediatr Emerg Care. 2004 Sep;20(9):579-87.

31. Kramer MS, Naimark L, Leduc DG. Parental fever phobia and its correlates. Pediatrics. 1985 Jun;75(6):1110-3.

32. Erkek N, Senel S, Sahin M, Ozgur O, Karacan C. Parents' perspectives to childhood fever: comparison of culturally diverse populations. J Paediatr Child Health. 2010 Oct;46(10):583-7.

33. Chiappini E, Parretti A, Becherucci P, Pierattelli M, Bonsignori F, Galli L, et al. Parental and medical knowledge and management of fever in Italian pre-school children. BMC Pediatr. 2012 Jul 13;12:97.

34. Trippella G, Ciarcià M, de Martino M, Chiappini E. Prescribing Controversies: An Updated Review and Meta-Analysis on Combined/Alternating Use of Ibuprofen and Paracetamol in Febrile Children. Front Pediatr. 2019;7:217.

35. Chang L-C, Liu C-C, Huang M-C. Parental Knowledge, Concerns, and Management of Childhood Fever in Taiwan. J Nurs Res. 2013 Dec;21(4):252-60.

36. Nijman RG, Oostenbrink R, Dons EM, Bouwhuis CB, Moll HA. Parental fever attitude and management: influence of parental ethnicity and child's age. Pediatr Emerg Care. 2010 May;26(5):339-42.

37. van Stuijvenberg M, de Vos S, Tjiang GC, Steyerberg EW, Derksen-Lubsen G, Moll HA. Parents' fear regarding fever and febrile seizures. Acta Paediatr Oslo Nor 1992. 1999 Jun;88(6):618-22.

38. Walsh A, Edwards H, Fraser J. Parents' childhood fever management: community survey and instrument development. J Adv Nurs. 2008 Aug;63(4):376-88.

39. Cinar ND, Altun I, Altınkaynak S, Walsh A. Turkish parents' management of childhood fever: a crosssectional survey using the PFMS-TR. Australas Emerg Nurs J AENJ. 2014 Feb;17(1):3-10.

40. Kelly L, Morin K, Young D. Improving caretakers' knowledge of fever management in preschool children: is it possible? J Pediatr Health Care Off Publ Natl Assoc Pediatr Nurse Assoc Pract. 1996 Aug;10(4):167-73.

\section{Figures}




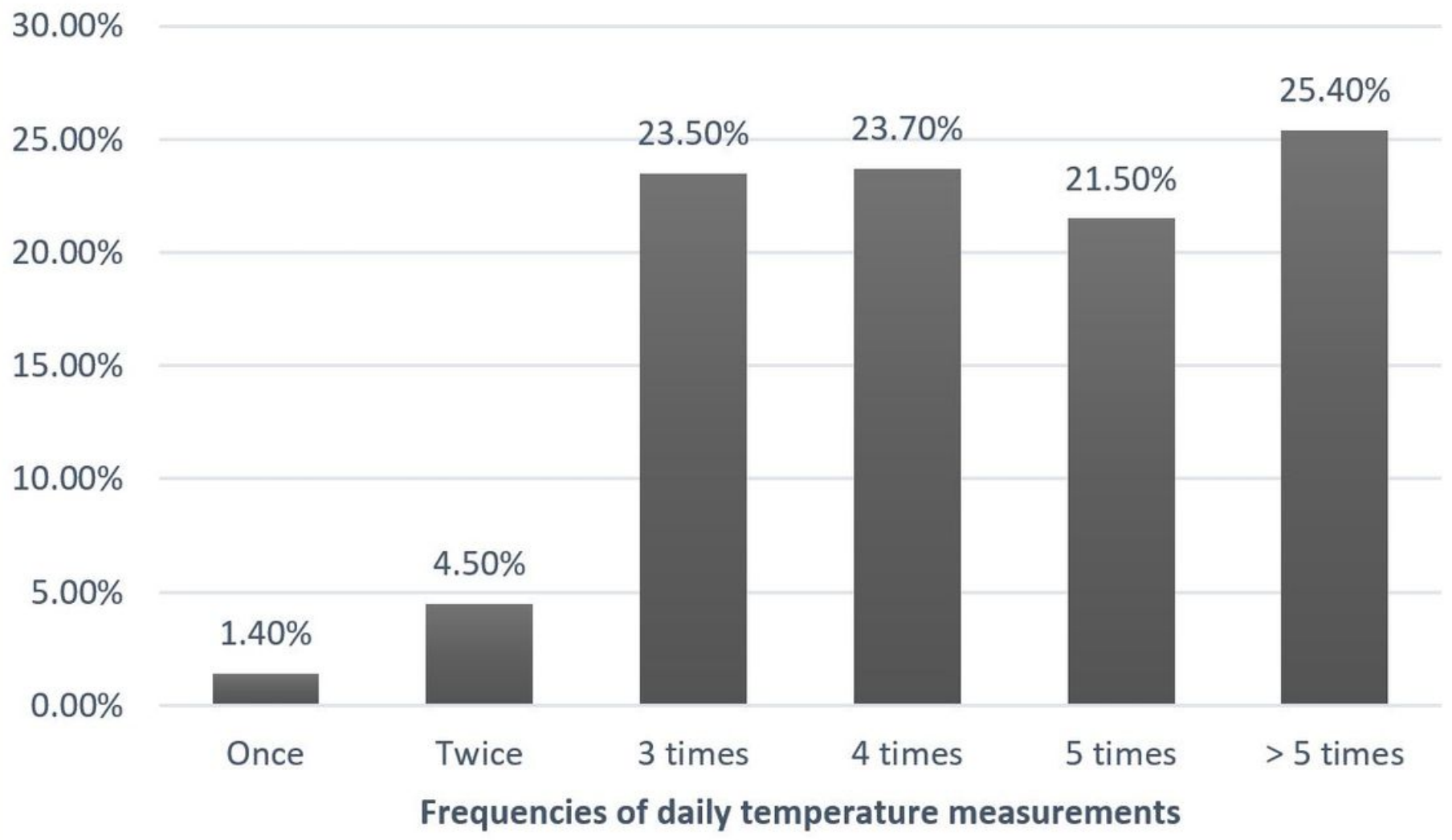

Figure 1

Frequencies of daily temperature measurements 


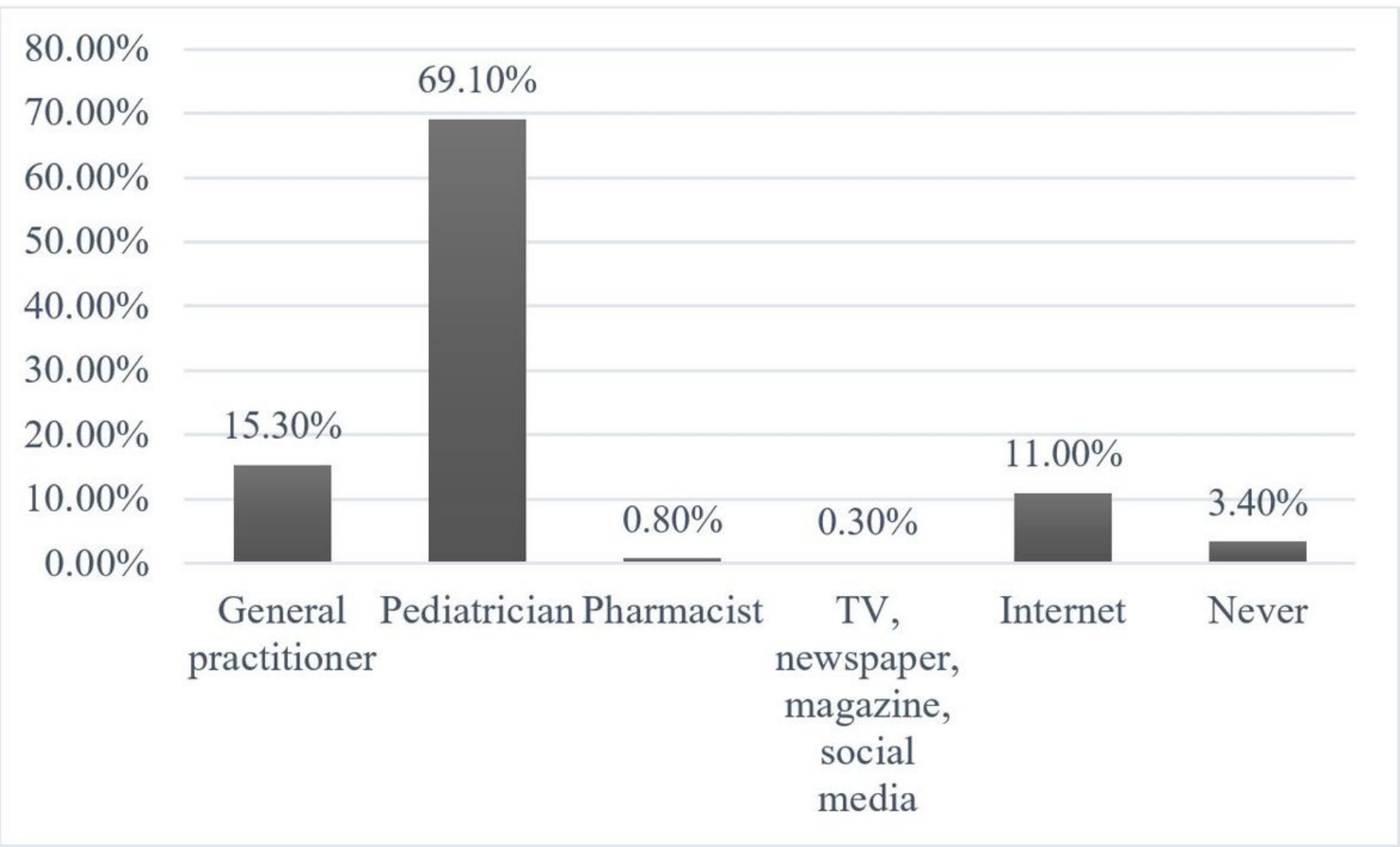

Figure 2

Sources of information regarding pediatric fever 